\title{
O sonho como uma produção social
}

LAHIRE, Bernard. L'interprétation sociologique des rêves. Paris: La Découverte, 2018. 490p.

\section{Bruno Costa Barreiros* Débora Previatti*}

\section{Resumo}

Considerando a expressão onírica como uma realidade individual intrinsecamente social, Lahire propõe uma fórmula geral que ambiciona uma melhor compreensão do processo de fabricação dos sonhos. Para isso, a argumentação do autor, apresentada e discutida nesta resenha, contempla desde um retorno crítico a Freud até a sistematização de uma perspectiva disposicionalista-contextualista, na qual os relatos oníricos e seus contextos de produção adquirem destaque analítico.

Palavras-chave: sonhos, Bernard Lahire, sociologia, psicanálise.

\section{The dream as social production}

\section{Abstract}

In considering dreaming as an intrinsically social individual reality, Lahire proposes a general framework that seeks a better understanding of the dream-making process. In this sense, the author's argument, which we present and discuss in this review, includes both a critical return to Freud and a systematization of a dispositionalcontextualist framework that provide an analytical approach to accounts of dreams and their contexts of production.

Keywords: dreams, Bernard Lahire, sociology, psychoanalysis.

* Universidade Federal de Santa Catarina, Florianópolis, SC, Brasil. 

obra L'interprétation sociologique des rêves de Bernard Lahire ${ }^{1}$ compreende dois volumes. O primeiro, de que trata esta resenha crítica, envolve o que o autor concebe como um momento experimental de invenção teórico-metodológica empiricamente fundada; o segundo, ainda a ser publicado, contemplará um momento de exploração sistemática, teórica e metodologicamente guiada. Desse modo, o presente volume visa, a partir de relatos de sonhos ou de extratos de sonhos, provar a pertinência e a fecundidade do modelo teórico ou ferramentas metodológicas associadas.

Para Lahire, o sonho é um objeto inquietante e sedutor. Trata-se de um produto da imaginação, no qual os indivíduos que sonham vivenciam esse momento como se estivessem imersos no mundo real. Nem sempre é lembrado ao acordar, na maioria das vezes é alterado ou esquecido e aí reside uma dificuldade sem limites do pesquisador que tem o sonho como objeto de estudos, já que depende, fundamentalmente, do relato dos indivíduos. O relato, por vezes, é bizarro, incoerente, delirante ou incongruente, tanto aos olhos do pesquisador como do próprio indivíduo que sonha. Nesse sentido, Lahire adverte que tomar os sonhos como objetos de pesquisa constitui uma árdua empreitada teórico-metodológica.

Lahire avalia que as ciências sociais pouco contribuíram com estudos do sono e do sonho ao longo da história. O sonho, tomado como uma produção mental involuntária, aleatória e atemporal, foi, por muito tempo, um objeto de estudos negligenciado por sociólogos, antropólogos ou historiadores. Exceções foram os historiadores Peter Burke, Jacques Le Goff e Jean-Claude Schmitt, que lançaram pistas para a elaboração de uma história social ou cultural dos sonhos. Além disso, o sonho apareceu

\footnotetext{
${ }^{1}$ Atualmente, Bernard Lahire é professor de sociologia da École Normale Supérieure de Lyon (Centre Max Weber) e membro sênior do Institut Universitaire de France. Esta frente de trabalho sobre os sonhos dá prosseguimento ao seu itinerário como pesquisador, marcado pelo questionamento das fronteiras disciplinares entre psicologia e sociologia, a exemplo de seus livros L'Homme pluriel (1998), Portraits sociologiques - Dispositions et variations individuelles (2002), Franz Kafka - élements pour une théorie de la création littéraire (2010) e Dans les plis singulier du social (2013).
} 
em algumas reflexões sociológicas tais como: nas de Émile Durkheim (em 1883-1884, em algumas páginas do resumo de uma aula dedicada ao sono e ao sonho); de Maurice Halbwachs, sobretudo sobre a reflexão do sonho a partir dos quadros sociais da memória; de Roger Bastide, o qual escreveu o artigo "Matériaux pour une sociologie du rêve" na Revue Internationale de Sociologie em 1932. Com exceção das reflexões de Halbwachs, as contribuições científicas mais sólidas para a elaboração de uma ciência social dos sonhos vieram do outro lado do Atlântico. É o caso dos trabalhos pioneiros de Mary Whiton Calkins e do psicólogo Calvin S. Hall.

Foi em 1997, em uma passagem de Lahire pela Universidade de Berkeley, que ele entrou em contato, por acaso e curiosidade, com as premissas de uma sociologia dos sonhos. Desde então, foram vinte anos de leitura e trabalho junto a outros pesquisadores até chegar à presente obra. A partir desses estudos acumulados sobre o sonho, mobilizados a partir de diferentes disciplinas (psicanálise, neurociências, psicologias, linguística, sociologia, antropologia, história etc.), Lahire elaborou uma teoria geral da expressão onírica, que parte do modelo de interpretação sintético proposto por Sigmund Freud, porém buscando corrigir suas falhas, faltas e erros. Tal teoria, que passa por compreender o processo de fabricação do sonho, culmina na elaboração de uma fórmula geral de interpretação dos sonhos.

A concepção de Lahire sobre o sonho é a de que este deve ser pensado enquanto uma forma de expressão que se situa em um continuum expressivo (sonho, alucinação, delírio, expressão artística ou criação literária etc.) e que varia conforme as condições nas quais a atividade psíquica é produzida. A teoria da expressão onírica formulada a partir da sociologia, defendida por Lahire, incorpora conhecimentos multidisciplinares e aborda o sonho por meio de uma perspectiva disposicionalista e contextualista. Para Lahire, passado incorporado, problemática existencial, eventos desencadeadores - do passado recente, incluindo o dia do sonho - e o contexto do sono se articulam na produção onírica. Sob essa ótica, a teoria elaborada por 
Lahire é "um ensaio de síntese conceitual e de reapropriação crítica" ${ }^{2}$ (p. 48) de uma série de resultados parciais, teórico-empíricos, de diversos pesquisadores, sobretudo a partir da primeira grande síntese realizada por Freud.

Endossando a premissa básica freudiana de que o inconsciente é mais decisivo do que a consciência para explicar as ações humanas, Lahire se afina com a psicanálise e ataca os que insistem que apenas os objetos diretamente verificáveis são relevantes. Lahire pondera que os esquemas, as disposições, o passado incorporado e o inconsciente são apenas observáveis por meio de seus efeitos, ou seja, de forma indireta, o que não os desmerece como objetos de pesquisa. Sobre o passado incorporado, Lahire explica que este agiria sobre o presente de três maneiras diferentes: 1) pela ativação prática nas ações e interações da vida cotidiana; 2) como pano de fundo em expressões simbólicas, a exemplo do que ocorre no caso dos sonhos e dos atos artísticos; 3) pela lembrança visual ou verbal de cenas ou situações fundadoras desses esquemas, que são apreensíveis através de entrevistas, psicoterapias e outros relatos de maior profundidade. De toda forma, são as situações do presente que abrem o terreno para que o passado incorporado se manifeste.

Para elaborar sua teoria, Lahire parte muito da produção de Freud, mas a contextualiza na história da produção intelectual sobre os sonhos. Lahire mostra, exaustivamente, que uma série de pesquisas anteriores ao pai da psicanálise tornou possível o seu trabalho. Sobre essa produção intelectual pré-freudiana, Lahire destaca, por exemplo, os numerosos pesquisadores que, ao longo do século XIX, passam a anotar os seus próprios sonhos ou de seus próximos, a fim de melhor compreendê-los. Entre as pesquisas mais sistemáticas e precisas estão as de autores franceses, belgas e alemães, tais como: Moreau de la Sarthe, Gotthilf Heinrich von Schubert, Théodore Jouffroy, Léon d'Hervey de Saint-Denys, Joseph Delboeuf, Antoine Charma e Alfred Maury.

${ }^{2}$ Na passagem original: "un essai de synthèse conceptuelle et de réappropriation critique" (p. 48). 
Como todo grande autor original, muitas das noções trabalhadas por Freud advieram de autores precedentes: a simbolização, a dramatização, a condensação, o inconsciente, o papel secundário de estímulos corporais internos como estímulos externos durante o sono para a fabricação dos sonhos, a censura, a transferência e a projeção etc. Conforme Lahire, o que Freud fez foi um trabalho extraordinário de reapropriação de uma infinidade de objetos, de fontes diversas, selecionando, triando, limpando, reparando e montando como se ele se encontrasse diante de inúmeras peças de Lego $^{3}$. Na avaliação de Lahire, este trabalho, além de não ter iniciado com Freud, também não iria terminar com ele.

Essa abordagem, alinhada a uma visão de progresso científico, é defendida por Lahire, que se posiciona em relação a visões mais relativistas que tendem a dissipar o processo "integrador" e "cumulativo" na história dos estudos sobre sonhos. Certos trabalhos históricos ou etnológicos sobre o sonho colocam em xeque essa perspectiva, de modo a entender que cada sociedade possui os seus usos sociais próprios dos sonhos, sua própria lógica e sua própria razão, dando a impressão de que os estudos dos sonhos não avançaram ao longo do tempo. Entretanto, Lahire argumenta que a história dos modos de apropriação (tipos de reação e de interpretação) dos sonhos não interrompe a história dos avanços científicos no que diz respeito à produção de conhecimento dos fatos oníricos.

Para Lahire, essas duas visões conflitivas levam a uma encruzilhada, porém a saída é simples. Tratam-se, sobretudo, de objetos muito distintos: o primeiro é a atividade humana em torno de um fato, ou seu ambiente e que diz respeito ao relato do sonho, que é problematizado em termos de seus usos e suas apropriações; já o segundo, o qual o autor se propõe a analisar, é a atividade humana que gera o fato em questão, a saber, o próprio processo de fabricação das imagens do sonho e de seu relato. Assim, há duas grandes formas de abordar os sonhos nas ciências sociais e humanas. Podemos nos concentrar sobre os modos como o sonho é contado,

${ }^{3} \mathrm{Na}$ passagem original do texto: "Tout se passe comme si Freud était placé devant un amas d'objets (...) parmi lesquels se trouveraient des nombreuses pièces de Lego". (p. 21) 
compartilhado, difundido, tratado e interpretado pelas diferentes sociedades, grupos ou categorias de indivíduos; ou, de outra parte, dedicar-se ao estudo da fabricação e da significação dos sonhos, preocupando-se com a questão de por que sonhamos o que sonhamos e de que maneira o fazemos. Para Lahire, o primeiro modo é cientificamente legítimo, todavia não contribui de maneira decisiva para captar o sonho como objeto plenamente social.

O sonho é interpretável, inclusive, cientificamente. Entender que é possível uma interpretação científica dos sonhos pressupõe a certeza de que essa interpretação não é uma prática misteriosa, subjetiva, múltipla ou infinita, mas sim que se configura em um "enorme quebra-cabeças" ${ }^{\text {". }}$ O esforço metodológico de montá-lo só seria possível por meio do registro das sessões e de sua transcrição integral - o que habitualmente não acontece, na medida em que o analista jamais registra as suas sessões, apenas faz anotações sobre o que o paciente fala.

Em um ataque importante à teoria de Freud, Lahire afirma que ele teria adotado concomitantemente duas concepções ontológicas opostas. Numa primeira, o indivíduo seria socializado, desenvolvendo uma psique determinada pelas relações intrafamiliares precoces. Já a outra aponta para um indivíduo biológico dominado pela libido sexual. Lahire alerta que, mesmo quando pende em direção a uma concepção de indivíduo socializado, o que Freud considera no ambiente intrafamiliar não contempla as dimensões de análise utilizadas pelos sociólogos. Na psicanálise clássica, os pais, as mães e os irmãos parecem não ter formações escolares, profissões, idades, nem mesmo pertencimentos nacionais, atividades culturais ou políticas. Freud teria esquecido, ao desenvolver a sua noção de complexo de Édipo, que o mito original (i.e., Édipo rei) se tratava de alguém que era um monarca e que isso indicaria uma posição social dominante, a qual estaria indissociável de suas ações. Em outros momentos de seu livro, Lahire ameniza essa crítica e pondera que ter como foco de análise o ambiente intrafamiliar não é propriamente um erro: afinal, os indivíduos não nascem

${ }^{4} \mathrm{Na}$ passagem original do texto: "un énorme puzzle où les pièces sont assemblées peu à peu pour recomposer l'image globale finale" (p. 44). 
em classes, mas em famílias. Entretanto, é justamente nas famílias que eles aprendem os modos de pensar e agir de suas classes, que ocorrem os primeiros processos de transmissão cultural.

Em outro ataque à psicanálise, Lahire afirma que Freud se via como uma espécie de criptólogo dos sonhos de seus pacientes, na medida em que acreditava que interpretar sonhos significava encontrar neles significados ocultos. Em Freud, o conteúdo manifesto de um sonho seria uma falsa mensagem que esconde a mensagem verdadeira, o conteúdo latente, o qual seria apreensível pelo psicanalista. Além disso, Lahire identifica um caráter paradoxal no argumento freudiano sobre a censura. Por um lado, ela é tão forte que impossibilita o trânsito fluido entre os desejos inconscientes recalcados e as vontades da consciência; por outro, a censura nunca seria tão fraca, tão relaxada, como na produção onírica. Na concepção de Lahire, isso cria uma confusão, pois passaríamos a duvidar se a formação dos sonhos está na força da censura ou em sua frouxidão durante o sono. Lahire acusa Freud de fazer uma "acrobacia argumentativa"5 para contornar essa contradição, na qual o principal erro estaria no pressuposto de que o conteúdo latente é o conteúdo verdadeiro, autêntico e livre, ao passo que o conteúdo manifesto seria hipócrita, contido e falso.

Uma outra crítica a Freud é a de que ele teria negligenciado a importância do registro escrito dos sonhos e das condições de produção dessas narrativas. Ele sequer estimulava que seus pacientes registrassem os sonhos por escrito: os relatos ocorriam apenas nas sessões clínicas, de forma oral, o que, por vezes, criava um abismo temporal importante entre o sonho e o seu relato. Uma vez que tomemos o registro escrito como fonte de análise sociológica, devemos considerar que o nível de instrução dos indivíduos que sonham possui um peso importante, na medida em que as pessoas menos escolarizadas tendem a apresentar relatos de sonhos menos detalhados do que aquelas mais escolarizadas.

${ }^{5} \mathrm{Na}$ passagem original do texto, Lahire se refere à "acrobacia argumentativa" da seguinte forma: «vouloir tenir les deux à la fois relève de l'acrobatie argumentative » (p.219). 
Dado que o sonho, para Lahire, é uma realidade individual intrinsecamente social, as neurociências jamais poderão explicá-lo sozinhas. Do mesmo modo, há que se indagar se análises literais de conteúdo, especialmente aquelas de caráter quantitativo, fazem algum sentido no caso dos estudos sobre sonhos. Imagens, sons e sensações elaboradas pelo indivíduo que sonha são produções simbólicas, que possuem relação tanto com as propriedades sociais desses indivíduos (idade, sexo, meio social ou profissional, grau de escolaridade, situação familiar etc.), como também estão condicionadas por suas experiências sociais, prévias e de longa data, mas também por aquelas próximas ao dia do sonho. Esse conjunto visual e sensorial produzido durante o sonho é, portanto, resultado de disposições e esquemas incorporados, mas que depende de seu contexto de criação, como toda produção social.

Os sonhos são "condensados de experiências sociais involuntariamente moldadas pelo indivíduo que sonha durante seu sono"6 e, devido a isso, segundo Lahire, todo sonho é autobiográfico. Isso não implica assumir que a transcrição de um relato onírico represente a vida do indivíduo que sonha, mas que o sonho é uma expressão de questões envolvidas na situação existencial em que o indivíduo é levado a se posicionar. Aqui, diferentemente do que ocorre, por exemplo, em relação às produções literárias, um determinado sonho de um indivíduo não é um posicionamento em relação aos sonhos de outros indivíduos que sonham. Desse modo, à luz da teoria dos campos, não existe um campo onírico: não há capital onírico a conquistar ou a redefinir, não há lutas ou concorrências entre os indivíduos que sonham, dentre outros elementos que definem um campo. Trata-se de uma comunicação de si para si mesmo, como Lahire define: uma linguagem interior e privada, sem, portanto, a necessidade de ser entendida por outros, o que promove um relaxamento da censura formal e da censura moral, ao contrário do que Freud predominantemente acreditava. Assim,

${ }^{6} \mathrm{Na}$ passagem original do texto: «condensés d'expériences sociales mises en forme involontairement par le rêveur durant son sommeil » (p. 94) 
para Lahire, a comunicação de si para si mesmo constituiria o mais íntimo dos diários íntimos.

Para Lahire, também faltou a Freud enfatizar as particularidades dos contextos de enunciação dos sonhos. Aparentemente incoerentes e deformados, como por vezes Freud considerava, os sonhos só podem ser entendidos se lembrarmos das características de seus contextos de enunciação, raciocínio válido a toda análise de atos linguísticos. Lahire afirma que as "deformações", passíveis de serem apreendidas a partir dos relatos oníricos, ocorrem menos em função de uma censura do superego e mais porque se trata de uma comunicação de si para si mesmo. Isto, para Lahire, explicaria os relaxamentos morais nos sonhos, pela ausência de julgamento moral exterior. A compreensão que ele faz sobre essa comunicação de si para si mesmo é também menos verbal e mais imagética, o que leva Lahire a trazer a metáfora do "cinema interior".

Para entender como as imagens são geradas nos sonhos, a categoria central é a analogia. Isso valeria também para os pensamentos que ocorrem em estado de vigília. As imagens se formam pela associação de coisas que possuem um "ar de semelhança". Isso ocorre porque os seres humanos são seres simbólicos, que possuem uma história e que têm a capacidade de interiorizar esquemas cognitivos e disposições. Além da associação por analogia, Lahire destaca a associação por contiguidade, o que indica que duas coisas se associam por serem vizinhas do ponto de vista cognitivo. Lahire sugere que uma das peculiaridades do sonho é precisamente a de misturar, por analogia ou por contiguidade, elementos que, na maior parte das vezes, estão dissociados na consciência ou no estado de vigília. Essa mistura é ainda mais complexa na medida em que isso ocorre entre imagens do presente e imagens do passado.

O trabalho da interpretação sociológica dos sonhos de um indivíduo ou de um grupo social passa por levantar, a partir do conjunto mais ou menos vasto de narrativas de sonhos, as estruturas comuns ou esquemas imanentes. A ideia de imanência é utilizada por Lahire para se posicionar contra interpretações universalistas dos sonhos (e.g. dicionários de sonhos) 
que aportam referências exteriores na interpretação das experiências oníricas singulares. Desse modo, para compreendermos os sonhos por meio de uma sociologia disposicionalista e contextualista, é preciso reconstituir três grandes elementos, a saber: 1) aqueles mais recorrentes do patrimônio de disposições incorporadas do indivíduo que sonha e do estado da sua problemática existencial, apreendido pelo estudo de sua biografia sociológica (por meio do estudo diacrônico de grandes classes de experiências socializadoras), passível de ser obtida por meio de longas entrevistas ou por meio de arquivos, no caso de falecidos; 2) as circunstâncias imediatas da vida diurna que suscitaram o sonho em questão, captadas mediante entrevista do indivíduo que sonha; e 3) o quadro específico de expressão onírica, cujas características mostram que os sonhos não são produções espontâneas e fora de contexto, mas que respondem a lógicas muito precisas.

A biografia sociológica envolveria, ao contrário de pressupor conflitos típicos e universais (e.g. complexo de Édipo), uma reconstrução das situações recorrentes reais do passado do indivíduo que sonha, as quais modelariam seus comportamentos no presente. Para tanto, Lahire enfatiza as experiências de socialização (e.g. familiar, escolar, profissional, sentimental, política, religiosa, esportiva), que constituíram esse mesmo indivíduo e que se tornam incorporadas sob a forma de esquemas e disposições de crer, ver, sentir e agir. O trabalho do sociólogo consistiria, então, em fazer entrevistas com os indivíduos que sonham, por vezes mais de uma com cada participante, a fim de mapear todos esses elementos, contrastando esses dados com os relatos oníricos.

Para compreender os problemas existenciais dos indivíduos, Lahire acredita ser mais frutífero utilizar métodos sociológicos de objetivação das trajetórias biográficas do que se apoiar em filósofos existencialistas. Em Lahire, os problemas existenciais de um indivíduo dizem respeito ao conjunto de problemas enfrentados ao longo de sua vida. Esses problemas têm como origem o conflito entre disposições primárias incorporadas junto à família e as disposições secundárias divergentes ou, ainda, a dissonância entre disposições e contextos específicos de vida. 
Para construir uma fórmula geral de interpretação do sonho, Lahire retoma seu esquema básico disposicionalista-contextualista. Este pode ser resumido da seguinte maneira: Disposições $>$ Contextos de ação $>$ Práticas, ou ainda, Passado incorporado $<>$ Contexto de ação presente $>$ Práticas. As práticas são sempre formação de compromisso (no sentido freudiano) entre um passado incorporado estruturante e os constrangimentos de um contexto no presente. Lahire lembra que o sonho não deve ser tomado como algo que flui sem constrangimentos, mas sim que estes são essencialmente internos. São gerados a partir dos esquemas e disposições, dos elementos estruturantes da problemática existencial do indivíduo e pelos estímulos psicofísicos que atuam como desencadeadores. Assim, no caso da interpretação sociológica dos sonhos, a fórmula geral disposicionalista-contextualista (Disposições $>$ Contextos de ação > Práticas) é desequilibrada a favor das disposições, do passado incorporado dos indivíduos.

É relevante destacar que Lahire enxerga certa sobreposição entre as noções de inconsciente de Freud e de passado incorporado com a qual ele e Pierre Bourdieu trabalham. Desse modo, o esquema da psicanálise seria: passado familiar incorporado $<>$ contextos de relação interpessoal presentes > comportamentos. Apesar de haver certa sobreposição, ele critica que a psicanálise tem a tendência de reduzir as experiências passadas a eventos-chave específicos. Isso incorreria no que ele chamou de um disposicionalismo mecanicista, no sentido de uma propensão a superestimar o passado familiar incorporado em detrimento de outras experiências e contextos desencadeadores vivenciados pelos indivíduos ao longo da vida. Para além da infância, Lahire questiona: e quanto à escola, aos grupos de amigos, às instituições religiosas, políticas, culturais, esportivas e profissionais?

O autor de L'interprétation sociologique des rêves aponta que alguns segmentos sociais possuem uma maior inclinação a se interessar pelos sonhos e, consequentemente, a se lembrar e fornecer relatos com maior facilidade. As mulheres seriam mais propensas a fornecer relatos de sonhos do que os homens, que Lahire justifica pelo que denominou de uma cultura feminina de intimidade, verificável, por exemplo, no hábito mais 
frequente entre as mulheres - ao menos na França - de ter diários pessoais desde a infância. Uma maior propensão a se lembrar dos sonhos também é vista entre as pessoas que trabalham com a psicologia e com práticas estimuladoras da introspecção, como os artistas, quando se compara com pessoas que participam de universos profissionais que estimulam mais a exterioridade e a objetividade. Isso ocorre porque, segundo o tipo de ocupação, as pessoas passam mais ou menos tempo divagando, imaginando, refletindo sobre elas mesmas etc. Desse modo, as disposições profissionais também entram como um fator desencadeador da lembrança dos sonhos e, consequentemente, de seus relatos. Por outro lado, em Freud, não há a consideração de que uma maior ou menor dificuldade de memorizar os sonhos estaria associada a variações culturais e sociais. Para Freud, o que está em pauta é, sobretudo, a questão da repressão dos desejos inconscientes.

Seria como se entre o momento presente de um determinado adulto que chegava ao consultório de Freud e o seu período da primeira infância nada tivesse ocorrido. Lahire chamou isso de "determinismo infantil"7 em Freud. Esse determinismo também seria sexual e libidinoso: assim, o homo psicanaliticus estaria centrado na libido sexual. Para Lahire, considerando o modo plural de desejos socialmente constituídos, existiria na realidade social tanto a libido dominandi (desejo de dominação) quanto a libido sexualis (desejo sexual). O erro de Freud em suas interpretações dos sonhos de reis e rainhas residia precisamente aí: quando esses indivíduos sonhavam com os seus pais e mães, Freud via apenas dramas sexuais intrafamiliares, sem perceber que essas figuras também representavam autoridade e poder.

Para a sua fórmula adaptada ao sonho, Lahire introduziu várias etapas e alguns elementos complementares. Essa fórmula é composta de uma primeira etapa - "estado de vigília pré-sonho" - na qual eventos, gestos e falas atuam como "gatilhos atrasados" de uma parte de esquemas e disposições incorporados; uma segunda, "quadro do sono", quando ocorre o sonho propriamente dito e diz respeito às condições cérebro-psíquicas-semióticassociais do sonho, pelas quais os esquemas de experiências são convertidos

${ }^{7} \mathrm{Na}$ passagem original, Lahire emprega a expressão « déterminisme infantile » (p. 124). 
em esquemas oníricos; e, uma terceira ("estado de vigília pós-sonho"), que é a lembrança do sonho, o relato oral para os outros ou o relato escrito do sonho. Por fim, o processo de fabricação do sonho pode ser esquematizado da seguinte forma: (1) Estado de vigília pré-sonho (Problemática existencial $<>$ Contexto pré-sonho $<>$ disposições) $>$ Estocagem na memória $>$ (2) Sono (Estímulos internos <> Quadro do sono $<>$ Disposições) $>$ Estocagem na memória > (3) Estado de vigília pós-sonho (Lembranças de sonhos $<>$ Contexto pós-sonho $<>$ Disposições) $>$ Relatos de sonhos ${ }^{8}$.

Em sua conclusão, Lahire frustra a expectativa dos que buscam em sua obra interpretações genéricas e sedutoras. Sua teoria não tem como objetivo dizer qual é a função dos sonhos e isso não é necessário para melhor compreendê-los. Além disso, os sonhos não teriam uma única função. Para Lahire, sonhamos porque vivemos e o pensamento não cessa. Outro ponto que Lahire retoma é que os sociólogos partem, ainda, em suas análises, da concepção de indivíduos com exageradas consciência reflexiva e vontade própria (portadores de gostos, preferências e representações, de interesses e valores conscientes) que, na prática, não possuem. Considerar o sono como um momento passivo, menos ativo em termos de simbolização, é cair em uma espécie de diurno-centrismo. Isso pode ser percebido pela negligência, na área das ciências sociais, de estudos que contemplem atos decorrentes de perdas de controle de si, como nas alucinações e nos delírios. Os sociólogos se interessariam apenas pelo estado de vigília, pelas condutas humanas publicamente organizadas, sem atentar a tudo que subjaz à racionalidade. Para entender a produção onírica, a sociologia não pode assumir o prisma das ilusões de liberdade e da vontade do sujeito. O que o estudo sociológico dos sonhos mostra é que o social age sobre os indivíduos, mesmo em seus momentos de retiro, em seus momentos de sono.

Em sua extensa obra L'interprétation sociologique des rêves, Lahire contribui para colocar os sonhos na agenda de pesquisa das ciências sociais. Sua empreitada, nesse primeiro volume, é notável tanto na qualidade do retorno crítico a Freud, quanto na sistematização original de uma perspectiva

${ }^{8}$ Fórmula adaptada e traduzida de Lahire (2018, p. 108). 
disposicionalista-contextualista que ambiciona uma interpretação sociológica dos sonhos. Por outro lado, na avaliação dos autores dessa resenha, o livro não consegue defender totalmente sua proposta analítica. O motivo principal é a ausência intencional de casos empíricos coletados e interpretados por Lahire. No escopo do que o autor denominou de momento experimental de invenção teórico-metodológica, esse primeiro volume peca, ao nosso ver, por uma lamentável dissociação teoria-empiria.

Desse modo, avaliamos que seria mais pertinente uma proposta que se ativesse menos ao resgate da psicanálise freudiana e mais a uma conjunção teórico-empírica, conciliando os debates teórico-metodológicos a sonhos de indivíduos, situados histórica e socialmente, já nesse primeiro volume. Isso facilitaria ao leitor uma melhor compreensão dos argumentos construídos pelo autor, de seus limites e potencialidades. Além disso, permitiria ver, mais claramente, em que medida tal proposta avança ou supera Freud e, também, aquele que inspirou muitos de seus trabalhos, Norbert Elias (2010), quem desenvolveu esforços muito semelhantes. De todo modo, resta-nos aguardar pelo segundo volume de L'interprétation sociologique des rêves e acompanhar o desenvolvimento dessa empreitada de Lahire.

Bruno Costa Barreiros é Doutor em Sociologia Política pelo Programa de Pós-Graduação em Sociologia Política, da Universidade Federal de Santa Catarina PPGSP-UFSC e membro integrante do Núcleo de Sociologia Econômica (NUSEC) e do METROPOLIS - Laboratório de Pesquisa Social.

$\equiv$ barreirosbc@gmail.com

Débora Previatti é Doutora em Sociologia Política pelo PPGSP-UFSC com estágio de doutoramento na École des Hautes Études en Sciences Sociales de Paris, integra o Núcleo de Pesquisa METROPOLIS - Laboratório de Pesquisa Social (UFSC).

$\equiv$ deborapreviatti@gmail.com 


\section{Referências}

1. ELIAS, Norbert. Au-delà de Freud. Sociologie, Psychologie, Psychanalyse. Paris: La Découverte, 2010.

2. LAHIRE, Bernard. L'Homme pluriel. Les ressorts de l'action. Paris: Nathan, 1998.

3. LAHIRE, Bernard. Portraits sociologiques. Dispositions et variations individuelles. Paris: Nathan, 2002.

4. LAHIRE, Bernard. Franz Kafka - Élements pour une théorie de la création littéraire. Paris: La Découverte, 2010.

5. LAHIRE, Bernard. Dans les plis singulier du social. Individus, institutions, socialisations. Paris: La Découverte, 2013.

6. LAHIRE, Bernard. L'interprétation sociologique des rêves. Paris: La Découverte, 2018. 